NBSIR 84-1698( $(\ell)$

\title{
AN ASSESSMENT OF
} ELECTROMAGNETIC INTERFERENCE (EMI) AND ELECTROMAGNETIC COMPATIBILITY (EMC) MEASUREMENT PRACTICES TO MEET U.S. ARMY AVIATION RESEARCH AND DEVELOPMENT COMMAND EMI/EMC REQUIREMENTS

National Bureau of Standards U.S. Department of Commerce Boulder, Colorado 80303 January 1984 



\title{
AN ASSESSMENT OF ELECTROMAGNETIC INTERFERENCE (EMI) AND ELECTROMAGNETIC COMPATIBILITY (EMC) MEASUREMENT PRACTICES TO MEET U.S. ARMY AVIATION RESEARCH AND DEVELOPMENT COMMAND EMI/EMC REQUIREMENTS
}

\author{
W. J. Alspach \\ C. K. S. Miller \\ G. R. Reeve
}

Electromagnetic Fields Division National Engineering Laboratory National Bureau of Standards U.S. Department of Commerce Boulder, Colorado 80303

January 1984

Prepared for:

U.S. Army Aviation Research and Development Command (AVRADCOM)

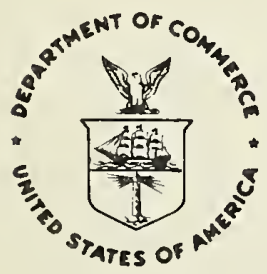

U.S. DEPARTMENT OF COMMERCE, Malcolm Baldrige, Secretary 

I. INTRODUCTION................................... 1

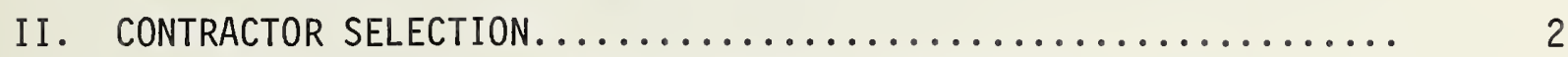

III. CONTRACTORS AND PRINCIPAL PERSONNEL CONTACTED............... 2

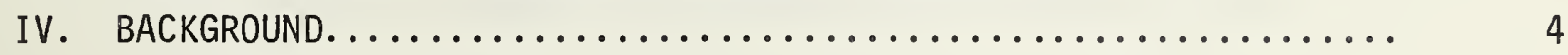

V. HISTORICAL PERSPECTIVE OF MILITARY SPECIFICATIONS........... 5

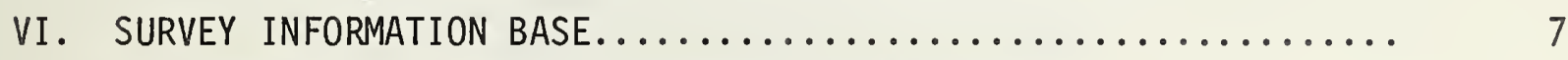

VII. EMI/EMC SPECIFICATIONS, STANDARDS, AND PRACTICES........... 7

VIII. EMI/EMC MEASUREMENT PROBLEMS........................ 12

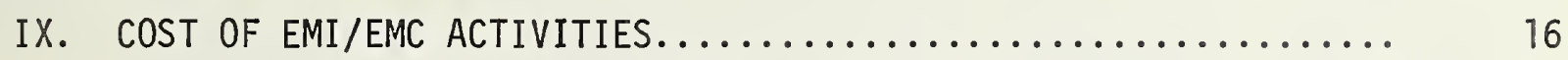

$X$. ELECTROMAGNETIC HAZARDS TO PERSONNEL AND EQUIPMENT........... 18

XI. AN NBS ROLE TO IMPROVE EMI/EMC MEASUREMENTS................. 18

XII. CONTRACTOR RECOMMENDATIONS FOR EMI/EMC TEST AND SPECIFICATION CHANGES AND OTHER CHANGES........................... 19

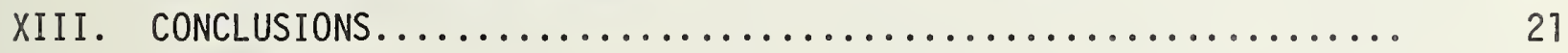

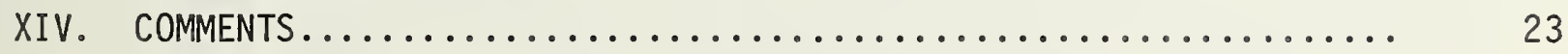



An Assessment of Electromagnetic Interference (EMI)

and Electroalagnetic Compatibility (EMC) Measurement Practices

to Peet U.S. Army Aviation Research and Development Comand

EMI/EMC Requirements

W. J. Alspach, C. K. S. Miller, and G. R. Reeve

Electromagnetic Fields Division

National Bureau of Standards

Boulder, Colorado 80303

A survey of selected industrial contractors, airframe maufacturers, and electronic test and calibration firms was conducted during June - August 1982 by the Electromagnetic Fields Division, National Bureau of Standards, to assess industrial and commercial testing and measurement practices used to meet electromagnetic interference/electromagnetic compatibility (EMI/EMC) requirements of the U.S. Army Aviation Research and Development Command (AVRADCOM). This survey addressed the cost of conducting EMI/EMC tests; whether or not electronic components, subassemblies, systems, and their testing met specified AVRADCOM EMI/EMC requirements; and whether the test practices, test equipment, and EMI/EMC requirements are appropriate. The following conclusions were reached: (1) Victim-source testing, although limited, is the only current EMI test that is meaningful for whole system testing. (2) It is questionable whether electronic systems will perform satisfactorily in a battlefield electromagnetic environment. (3) There is no correlation in EMI/EMC test practices; it is possible that electronic systems are overdesigned, overbuilt, and overtested. (4) Future issues such as high-level field testing and electromagnetic pulse (EMP) need to be addressed.

Keywords: electromagnetic compatibility (EMC); electromagnetic interference (EMI).

\section{INTRODUCTION}

A survey of various industrial contractors, air frame manufacturers, and electronic test and calibration firms was conducted in the time period June August 1982 by the Electromagnetic Fields Division, National Bureau of Standards (NBS) to assess industrial and commercial testing and measurement practices used to meet electromagnetic interference/electromagnetic compatibility (EMI/EMC) requirements of the U.S. Army Aviation Research and Development Command (AVRADCOM). 
NBS made this survey under the auspices of an agreement with AVRADCOM to "provide engineering and measurement assurance services" to the AVRADCOM Product Assurance Directorate, St. Louis, Missouri.

This survey addressed the following:

- Do electronic components, subassemblies, and systems and the testing (calibration) of such meet AVRADCOM specified EMI/EMC requirements?

- Are the EMI/EMC requirements appropriate?

- Are the test practices, test equipment, etc. appropriate to meet these requirements?

- What is the financial cost of conducting such tests?

The survey results consist of voluntary comments and suggestions made by those surveyed. The aim of the contractors is to improve EMI/EMC measurement assurance and reduce the costs of such assurance.

NBS does not necessarily approve, endorse, or disagree with these comments and suggestions. This document, rather, only reports on the comments and suggestions made as (1) a representation of the current state of EMI/EMC measurement practices, and (2) the perceived desire of industry to improve upon their measurement assurance practices while reducing the costs of such to their customers--the military and, in particular, AVRADCOM.

\section{CONTRACTOR SELECTION}

A list of industrial contractors who furnish sophisticated electronics components and systems (e.g., communications and navigation systems) and the more commonplace (e.g., electrical power generators) equipment for AVRADCOM's AHIP helicopter and AQUILA remote piloted vehicle programs was given to NBS by the Product Assurance Directorate. From this list, NBS selected several contractors to contact. Additionally, NBS selected certain airframe contractors (who furnished complete Army aircraft) and commercial test and calibration firms (who provide specialized EMI/EMC measurement services) for contact.

Personal visits were then made by NBS personnel to the selected contractors. In most cases, excellent cooperation was given by these contractors.

In addition to the commercial contractors, NBS personnel also visited Army personnel at Fort Monmouth, New Jersey, who are concerned with EMI/EMC measurements and requirements.

\section{CONTRACTORS AND PRIMCIPAL PERSONMEL CONTACTED}

The following is a list of all industrial contractors and their principal personnel visited for this EMI/EMC survey. Army personnel at Fort Monmouth are also listed. 
1. Sperry Flight Systems - Albuquerque, New Mexico

A7 Farquer - AH 64 Program Mgr.

2. Rockwell International/Collins - Cedar Rapids, Iowa

Merrill Ludvigson - Prog. Mgr., Govt. Avionics

Wilbur Evarts - Mgr., Evaluation Engineering/Product Assurance

Larry Mulbrook - Mgr., Communications \& Navigation

3. Lear Siegler - Maple Heights, Onio

Robert Feucht - Vice-President, Engineering

Laszlo Hormat - Sr. Project Engineer

Kenneth Arner - Chief Test Engineer

4. Westinghouse Defense \& Electronic Systems - Baltimore, Maryland

Andrew Lavoie - Mgr., Product Qualifications Lab

Alwyn Roberts - EMC Engineering

Tony Cesko - EMC Engineering

5. Fort Monmouth - New Jersey

Jerome Blackman - Actg. Dir. Center for Communications Systems

Warren Kesse7man - Center for Communications Systems

Colin MacDonne11 - Deputy Director, Logistics Engineering Direc-

torate

George Kopecky - Logistics Engineering Directorate

6. AEL Service Corporation - Farmingdale, New Jersey

Margaretta Stone - EMI/EMC Section Head

Gene Barber - EMI/EMC Engineer

William Wild - Facility Mgr.

7. Kearfott Division, Singer Co. - Wayne, New Jersey

Gus Stavis - Mgr., Advanced Development Dept.

Edgar Freud - Senior Engineer

Bud Jaeger - EMC Test Engineer

8. RCA/Government and Commercial Systems - Burlington, Massachusetts

A. Ama to - Mgr., Products Engineering

Stan Patrakis - Mgr., Products Design

Russ Williamson - EMI Engineer

9. Detroit Diesel Allison - Indianapolis, Indiana

Eugene Ervin - Supervisor, Electrical/Electronic Design

Gail Hill - Sr. Experimental Engineer

Robert Nelson - Development Engi neer

10. McDonnell Douglas Astronautics Co. - Huntington Beach, California

Kenneth A. Francis, Vice President, Engineering

W. E. Bounds, Chief Electronics Engineer

Robert Obelman, Avionics, Control \& Information Systems 
11. Northrup Co. - Anaheim, California

Harlen Beck, Manager, Support Services Engineering John Hornung, Manager, Systems Design

William B. Gaumer, Process Engineering Specialist

12. Litton Guidance and Control Systems - Woodland Hills, California

John M. Leonis, Director, Systems and Sof tware

Fred R. Motter, Manager, EMC Engineering

13. Hughes Helicopters - Culver City, California

Gerald A. Booth, Chief, Electrical Systems

14. Lockheed Missiles and Space Co. - Sunnyvale, California

Ivan Beck, EMC Engineering

Paul E. Bolande, Program Office

15. Elite Electronic Engineering Co. - Downers Grove, Illinois

Donald E. Schmit, EMI Engineer

16. Bell Helicopter Textron - Fort Worth, Texas

Richard C. Henschel, Manager of Avionics \& Electrical Systems John G. Mast, Group Engi neer, Avionics Design

Jack G. Dillard, Group Engineer, Standards \& Electronics Lab

Phil Smith, Group Engineer, Electronic Systems Lab

\section{BACK GROUND}

The Institute of Electrical and Electronics Engineers (IEEE), in their IEEE Standard Dictionary of Electrical and Electronics Terms (IEEE STD 1001977), defines EMI and EMC as:

electromagnetic interference. Impairment of a wanted electromagnetic signal by an electromagnetic disturbance.

and

electromagnetic corpatibility. The capability of electronic equipments or systems to be operated in the intended operational electromagnetic environment at designed levels of efficiency.

Thus, in the context of Army aircraft, EMI can (and, unfortunately, too often does) adversely affect the performance of electronic equipment and systems. This EMI can take the form of a radiated or a conducted signal and can cause, for example, garbled communications, a false alarm from a radar threat receiver, or erroneous navigation.

Further, an electromagnetic signal, whether intentional or inadvertent (interference), may adversely affect human health and well being. 
Still further, an electromagnetic signal, given the correct circumstances of frequency and power, may adversely affect military ordnance. For example, the electromagnetic explosive device (EED) used in ordnance may cause its detonation if the EED is exposed to certain electromagnetic signais for too long. To guard against detonation, great pains are of ten taken to shield the EED against such signals.

This points up the fact that Army aircraft, be they sophisticated electronic surveillance systems, well-armed helicopter gunships, or simple remotepiloted vehicles, with on board electronic systems may suffer performance degradation (even malfunction and crash) if such systems are not "properiy designed" and tested for electromagnetic threats.

To ensure that the electronic systems are "properly designed," certain testing specifications have been generated by the military and industry. These specifications are, for the most part, imposed upon industry (the component manufacturers as we 11 as the system integrators and the airframe contractors) by Department of Defense (DOD) contract requirements. These contract requirements call for the exposure of components to certain electromagnetic environments to determine that component performance is not degraded beyond certain limits. This exposure is frequentiy referred to as "electromagnetic susceptibility" or electromagnetic compatibility testing. Components are also tested to determine the electromagnetic radiation emitted by the component (one "black box's" EM emission can be another box's EM interference). This is referred to as "electromagnetic emission" testing.

Even with these testing specifications, electromagnetic interference and electromagnetic compatibility are difficult to determine because the measurement processes associated with such are imprecise or impractical. EMI is difficult to measure; therefore, interference is difficult to isolate as a specific or distinct problem. In some cases, the testing specification requirements are considered ambiguous and misleading. Additionally, testing methods called for in the specifications can be inadequate or inappropriate to such a degree that testing repeatability and measurement accuracy are seriously compromised. Individual component testing under these specifications is no assurance that the final end product (i.e., the electronic systems in the host vehicle) will "pass" system EMI/EMC testing--"the sum of the parts does not necessarily equal that of the whole system."

Unfortunately, this failure or shortcoming of testing and measuring under imposed specifications can, and does in the opinion of many industrial contractors, result in the overdesign of many components and systems. The contractors believe that they cannot afford EMI/EMC failures, so they overdesign. Such overdesign has its price--it costs DOD dearly in larger contract prices paid to system contractors and their suppliers.

\section{HISTORICAL PERSPECTIVE OF MILITARY SPECIFICATIONS}

Military specifications concerning EMI/EMC have been in existence for quite some time; thus, the rationale for and circumstances of these specifications becomes more obscure with the passing years. Accordingly, representatives from NBS visited Fort Monmouth, New Jersey for discussions with Army personnel who have been associated with EMI/EMC concerns for a number of years. These Army personnel were involved in, or were closely related to, the 
generation and evolution of EMI/EMC specifications. The following presents an historical perspective of these specifications and represents the memory and viewpoint of the Army EMI personnel visited.

of the three military services, the Navy has responsibility for the "coordination" of military specifications. For example, the preparation of specifications is the work of many from both industry and the military, but the gathering together of inputs and the final draft of specifications and their eventual issuance is a Navy function.

The primary military specifications concerning EMI/EMC, issued in about 1967, are MIL STD 461 and MIL STD 462. These were generated at the behest, if not insistence, of industry; who, for the lack of such specifications, apparently often found themselves at odds with the military and with each other in defining and determining (measuring) electromagnetic interference and compatibility. The lack of measurement consistency resulted in chaos. MIL STD 461 established performance limits, e.g., what electromagnetic environments should not cause electronic equipment degradation, or how much degradation is permissible. On the other hand, MIL STD 462 outlined the measurement practices, including recommended equipments, to be used for making such determinations. MIL STDS 461 and 462 probably represented the best available thought and technology of their day, about 1967.

When MIL STDS 461 and 462 were agreed upon and issued, they were intended to serve only as guidelines--not as mandatory requirements. That is, they were to be regarded as interpretive and subjective guidelines and not to be rigid rules and regulations (specifications). Apparently, iittle time passed before MIL STDS 461 and 462 assumed a position of specifications in DOD contracts.

At the time MIL STDS 461 and 462 were being generated, or shortly thereafter, it was determined by the EMI/EMC community that still another standard was needed: MIL STD 464. This standard was intended to serve as an electronic systems (as opposed to MIL STDS 461 and 462 serving as components test documents) test document and the Air Force was assigned responsibility for generating such. No MIL STD 464 came into being. The reason for this is now unknown.

Army EMI personnel at Fort Monmouth state that the Army does not have a "hard nosed approach" or attitude towards MIL STD 462, the test methods specification, even if such is called for in Army contracts. Instead, a contractor's EMI/EMC test plan is reviewed and, if the contractor proposes a "better" test plan than is the case with MIL STD 462, the Army will "listen to and consider such." Comments from the industrial firms contacted for this survey indicate that this "listen to and consider such" is an inconsistent practice of the many Army personnel involved in the total acquisition and program monitor process.

Present practice of the Army appears to be to use MIL STD 461, the performance limits specification, and appropriate Notices in its contracting requirements. These Notices are, essential1y, "modifications" of MIL STD 461. 
Meanwhile, MIL STD 461B, an updated version of MIL STD 461, has been issued and is apparently used by the other services. The Army does not use the $B$ version, apparently because a determination has been made by appropriate Army personnel that there is a "lack of sufficient measurement techniques" to meet $B$ version requirements.

There appears to be considerable dissatisfaction with MIL STDS 461 and 462, including updated versions, amongst the military and their contractors. This dissatisfaction is a reason why the Society of Automotive Engineers AE-4 Committees (a voluntary standards organization) offered to "rewrite MIL STDS 461 and 462." Apparently this offer is now about 15 years old and no "rewritten" specifications have as yet appeared from the committee.

\section{SURVEY INFORMATION BASE}

Early on in the survey, it was quickly and easily determined that the various industrial contacts' comments and suggestions could be categorized in the following subject areas:

- EMI/EMC specifications, standards, and practices

- EMI/EMC measurement problems

- Cost of EMI/EMC activities

- Electromagnetic hazards to personnel and equipment

- An NBS role to improve EMI/EMC measurements

- Contractor recommendations for EMI/EMC testing and specification changes.

Accordingly, al1 contractor comments, suggestions, etc. have been grouped into these subject categories. Some comments are "favorable" while some are almost like a cry of despair. This grouping constitutes the data base, i.e., the information base for this report, and essentially consists of a multitude of informational "bullets" that express the contractor's thoughts, ideas, wishes, etc. This data base is somewhat voluminous and is considered as private information since nearly all of the contacts were particularly frank and honest in their discussions, opinions, etc. The National Bureau of Standards respects all of the contacts for their openess and candidness and is grateful for such.

\section{EMI/EMC SPECIFICATIONS, STANDARDS, AND PRACTICES}

\section{Survey Information}

Contractor Comments:

- MIL STD 461 environment curves (requirements) do not necessarily correspond to the real world, not combat related with electromagnetic warfare (EW) considerations.

- MIL STD 461 requires measurements at own on-channel signals; this is ridiculous, especially for receivers. 
- Specifications are seldom met completely, hence we go to the Army for waivers.

- Specifications are designed for electrical power users, not for power generators, yet the same specs apply to both.

- Conducted emissions tests are a real problem; there is no correlation between labs of test results and, further, the conducted emissions tests are not necessarily related to host vehicle requirements anyway.

MIL STDS 461 and 462 (testing to such) are expensive to conduct and are not totally reliable for host vehicle testing; whole system testing is the one that really counts.

In some cases where EMI failures occur, (some contractors) will obtain a waiver for such rather than fix the problem.

- Someone really needs to determine, "What are military requirements for EMI?"

- The Army (and others) needs a production type EMI test method to assure that production items are the same as the original development mode 1 as far as EMI and EMC are concerned.

- In some cases, EMI standards are strictly enforced; whereas in other cases, exceptions (waivers) are sought and granted.

- No modern field survey information on EM tactical environments is available.

- At 1east $50 \%$ of test samples submitted for EMI testing fail to meet specification limits.

- Using MIL STD 461B with MIL STD 462 is a problem. An update of MIL STD 462 is needed.

- Equations for radiated emissions testing are horrible to use.

- Have to stop test procedures to make calculations.

- In helicopters, most EM interference is caused by onboard transmitting antennas.

- It is difficult to obtain approval for use of alternative test methods.

- With present specifications and test methods, there is no assurance that electronic components and systems will operate correctly in the final host vehicle. Sometimes, the systems integrators themselves cause EMI problems because of cabling, bonding, batteries, etc.

- There are problems with MIL STD 461B, e.g., power line testing. 
- The standard concerning "broad band" and "narrow band" testing is not clear and, consequently, leads to differing interpretations.

- The helicopter is a bad electrical environment:

- power generators are "noisy"

- austere electronic engineering is required

- the power bus has a lot of current flow at $28 \mathrm{~V}$ dc instead of an aircraft $400 \mathrm{~Hz}$ ac

- ground return is through a sparse structure.

- Present EMI specifications are essentially radio oriented and, thus, are antiquated because they do not reflect a true electromagnetic situation; for example, an EW environment.

- The Army's Notice 4 (for use with MIL STD 461) covering conducted emissions is not compatible with Air Force and Navy requirements.

(We) do not have problems in obtaining approvals for use of alternative equipments, e.g., use of a spectrum analyzer for narrow band measurements.

- (We) perform EMI qualification testing only--no production sample testing.

- (We) have problems with EMI/EMC requirements being realistic.

- When test results are "out of spec," waivers are negotiated--generally successfully.

- MIL STD 4618 transients are outlandish--call for suppression of $100 \mathrm{~V}$ power spikes. (We) question reality of a $100 \mathrm{~V}$ power spike.

- Radiated emission levels are far lower (60 to $70 \mathrm{~dB}$ ) than susceptibility levels. Meeting such emission levels is very costly.

- Specifications call for absorbing a $20 \mathrm{~V}$, peak-to-peak, on-the-powerline bus, but yet cannot put more than $3 \mu \mathrm{V}$ on the bus. Cannot understand rationale for this, either.

- (We) cannot rely on military specifications (MIL SPECS) to define the EM environment. Design experience and testing assessment are much more meaningful than are specs.

- There is adequate regard for EMI in the early stages of a project; however, such regard steadily declines as time goes on.

- Contractor bids are high because the request for proposals (RFP's) ask for too many EMI requirements that are not relevant--literally, a barrage of such requirements.

- We test to MIL STDS 461 and 462 which are, generally, more stringent than needed. 
- We impose MIL STDS 461 and 462 on our suppliers even though we are aware that the components from our suppliers, when meeting these requirements, can still cause system EMI/EMC problems.

- We bend MIL STDS 461 and 462 to fit the system.

- (We) now have $200 \mathrm{~V} / \mathrm{m}$ exposure requirements. Handbook 235 (Navy test document), however, requires $5000 \mathrm{~V} / \mathrm{m}$ tests.

- Occasionally, customers do not have sufficient EMI consciousness. NASA is best for such; whereas the Army is more lax in this than are the Air Force and the Navy until a crisis arises, then it overreacts.

- The mast-mounted sight for Army helicopters will not be subject to (our) configuration controls and will have to rely on Army controls for such. A modified MIL STD 461 applies to this sight; it is felt that this specification does not reflect the battlefield EM environment in which the sight is to operate.

- In the case of the mast-mounted sight, the helicopter onboard equipment is probably the worst EMI threat--particularly the high frequency (HF) communications gear.

(We) do not presently have sufficient inhouse expertise for all EMI testing problems; (we) hire an outside consultant for EMI analysis work.

There is questionable validity of MIL STDS 461 and 462 values in relation to the real world environment. (We) are not sure if we overdesign equipment or not to meet these values.

We maintain a form of configuration control for EMI/EMC; however, once our products leave our plant we lose such control. We do, however, state our external wiring requirements to the system integrator to attempt to achieve total configuration control. Certain integrators do get us into trouble because they don't follow our requirements for control.

We impose EMI requirements on our vendors who, in turn, use commercial test houses. Sometimes these test houses do not follow test plans.

- We do not have many problems when our black boxes are installed in the host vehicle; we conclude by this that our equipment is "overdesigned."

We have a couple of peeves regarding EMI/EMC: 1) the downgrading of EMC board activity at the integrator under the direction (control) of customer. 2) It's a joke to require field levels of $100^{\prime} \mathrm{s}$ of $\mathrm{V} / \mathrm{m}$ at frequencies above $1 \mathrm{GHz}$ because such doesn't cause problems here; it will, however, cause problems at lower frequencies.

Obtaining waivers for EMI/EMC compliance is not a normal order of business with us. Some of our competitors, however, are of the buildtest-obtain waiver school. 
In some cases (electronic countermeasures), the EM emissions limits are not severe enough.

The Army's Notice 4 is a good attempt at more realistically defining EMI requirements.

(The) military regards specifications as sacred documents. We are lenient with our suppliers for specification deviations. The military is inconsistent with specification derivations; they readily give waivers for weapons which they understand, but not for electronic systems which they do not understand.

MIL STD 461 with Notice 3 is a pretty good document. Notice 4 (the Army document) is a confusing document.

There is no test requirement to validate vehicle performance in a battlefield EM environment. Further, no vehicle (EM) emissions signature measurements are required.

Some helicopters use a fair amount of composite materials that are poor for EM shielding purposes.

Sometimes, customer wi11 permit "tailoring" of MIL STDS 461 limits. In most cases, however, Army and Navy will not permit deviations unless time allows for redesign.

In the lower frequency bands, $20 \mathrm{~Hz}$ to $15 \mathrm{kHz}$, the limits (MIL STD 461) are too loose; whereas, in the band $20 \mathrm{MHz}$ to $200 \mathrm{MHz}$, the limits are too tight.

Whenever large variations in test results occur, resolution of the problem is between the customer and (our) program office. Time is important in such decision making. If time is tight, the decision is "liberal."

The Army and Air Force say they will not use MIL STD 461B, a Navy generated specification. MIL STD 462A lacks the test methods required by 461B. Further, the Air Force and the Army do not like each others "changes" which are now incorporated into $461 \mathrm{~B}$.

EMI specifications are too 10ose--too nebulous for practical matters, not definitive.

We have to "negotiate" each and every contract involving EMI measurements.

Presently, (our) test facilities have a $200 \mathrm{~V} / \mathrm{m}$ capability in the 10 $\mathrm{kHz}$ to $18 \mathrm{GHz}$ range. The Navy talks of new specifications calling for pulsed levels to $10,000 \mathrm{~V} / \mathrm{m}$ at $33 \mathrm{GHz}$ (We) are not considering offering test capabilities at levels greater than $200 \mathrm{~V} / \mathrm{m}$.

(We) question the technical knowledge of Army EMI personnel and their ability to make proper technical decisions. 
- EMI knowledge varies with the services. Air Force is more technically astute, whereas Army is conscious of the problem but its knowledgeable people are spread pretty thin.

- In the last 10 to 15 years, (we) have had to resort to specification waivers only a few times; this was for system testing. In the light of this, (we) suspect overdesign of equipment.

- Component testing does not guarantee a system passing specification requirements. However, as a general rule, component testing is $\mathrm{OK}$.

- (We) claim repeatability of measurements in a screen room to within a couple of dB. (We) take special care in keeping test set ups as identical as possible, as close to end use in aircraft.

- (We) are performing more and more host vehicle cabling "hot mockup" testing because cabling is becoming more of a concern.

- (We) have no problems using a spectrum analyzer in place of a receiver. Such is OK with AVRADCOM, Air Force, and Navy.

(We) do not use outside EMI consultants or test laboratories. (We) have a concern, however, for the quality of such test laboratories.

\section{EMI/EMC MEASUREMENT PROBLEMS}

\section{Survey Information}

\section{Contractor Comments:}

- MIL STDS permit no use of alternative test methods; waivers for such, however, are sometimes obtained. This points out inconsistency in the test me thodol ogy.

- In some cases where "failures" occur, the test is rerun with a different test configuration and then the item "passes."

- There appears to be little correlation between component testing and system testing results. The sum of the parts is not always equal to the whole.

- At least $50 \%$ of test items submitted to an independent test facility fail EMI/EMC tests.

- (We) always have troubles with high frequency EMI testing on host vehicles because of resonance phenomena.

- MIL STD 461 probably requires overdesign (and $\cos t$ ) but the degree of such overdesign is unknown.

- Screen room testing is a joke! 
(The) repeatability of cabling is a major problem to system integrators.

- Cross coupling of cables (routing within a bundle) is another source of EMI difficulty.

- Interaction between individual black boxes is a most serious problem.

Overdesign of equipment is necessary to pass EMI/EMC tests; there is no opportunity to optimize design for a cost/performance trade off.

(We) like victim-source test for whole system testing. However, (we) have never heard of any system meeting all of MIL STD 461 requirements; waivers for "failures" are used.

There is no correlation between laboratories for radiated emission and susceptibility testing. In fact, there is a lack of repeatability in the test methods themselves. We, ourselves, suffer from a lack of inhouse repeatability of test results.

- Twenty $d B$ or more variations (repeatability) have been noted in testing.

- A commercial power supply after rework now fails EMI tests. Rework had removed critical parts. However, even with replacement of these parts the unit still fails test. This indicates lack of EMI knowledge and training plus a lack of configuration control and sample testing to prevent such.

- Test methods for EM susceptibility are not realistic and levels are antiquated.

- Screen room testing is nonsense:

- no repeatibility

- specified antennas are inadequate

- customers; however, require such testing

- have noted test variations as high as $60 \mathrm{~dB}$ (1000 to 1$)$.

There is a lack of EMI consciousness on the part of all parties concerned.

Test equipment used for EMI testing is itself susceptible to EMI unless particular care is taken to prevent such.

Biconical antenna used for radiated susceptibility testing is inadequate for purpose intended.

Antenna factor for biconical antennas is meaningless.

Radiated susceptibility measurements above $30 \mathrm{MHz}$ cause problems.

(We) use some antiquated equipment for making these measurements. 
- (We) question the relationship between subsystem and whole system testing.

- (We) have repeatability problems with screen rooms--repeatability is worse at high field levels.

- Most of our EMI/EMC problems are with components meeting MIL STD 461 and 462 requirements rather than with system problems.

- MIL STD 461 does not address the $28 \mathrm{~V}$ power supply system for susceptibility requirements. NASA has a better specification for such.

- There are lots of things wrong with the test methods defined for radiated susceptibility testing--screen room variations!

- Screen rooms are OK for conducted emissions testing but pose problems for radiated emissions measurements. (We) have had $12 \mathrm{~dB}$, easily, variations (repeatibility) in our screen room measurements.

- We can test at exposures up to $200 \mathrm{~V} / \mathrm{m}$ but no higher--where some new requirements are appearing.

- A helicopter environment is a difficult EM environment because:

- electrostatic discharge

- lightning

- no shielding--they are flying panels.

- (We) have had problems in calibrating probes and to use such for test leveling purposes. NASA approves such use readily. New measurement techniques are adequately reviewed and approved by NASA; DOD organizations, however, do not really read measurement test plans.

- There is some question as to whether or not the EM emissions requirements of MIL STD 461 are realistic.

- EMI testing uses archaic methods:

- doesn't mention use of spectrum analyzer

- no mention of TEM cell

- test methods are out of date, i.e., transient response requirement.

- MIL STDS 461 and 462 do not acknowledge or allow the latest in testing equipment capabilities, e.g., does not respond to computer technology as applied to aerospace problems.

- Victim-source testing for system testing is not always a reliable EMI system test. We do not know of any integrator who runs a real system test on the whole vehicle.

- We obtain 6 to $10 \mathrm{~dB}$ repeatability in our screen rooms. 
- Our biggest problem is with the standing waves in a screen room.

- Photos are vital for test set up repeatability; that is, they are necessary to replicate the test set up.

If high fields exposure and EMP requirements become real, we will have serious testing problems.

It would be nice if there was one source to deal with EMI issues as opposed to the present system.

CSO2 (Conducted Susceptibility) is a problem test area. Power leads "exercising" components themselves "pick up" EMI.

The upper limit (frequency) of radiated susceptibility is also a problem area. Screen rooms are not a good means for making such measurements.

(We) have no screen room for high level testing, e.g., a customer requirement for $265 \mathrm{~V} / \mathrm{m}$ test. (We) will, instead, use inhouse anechoic chamber for this test.

Most testing difficulties with components are at the higher frequencies.

(Our) small screen rooms have experienced resonance problems, a 6 dB variability in radiated susceptibility measurements and a 20-30 dB variability in radiated emissions measurements.

The lack of EMC knowledge by vendors prevents the use of better testing methods.

We have experienced 25 to $30 \mathrm{~dB}$ variations when doing component testing in screen rooms. In screen room testing it is important to "duplicate" test set ups to ensure repeatibility.

MIL STD 461 does not differentiate between signal and power lines. We require our vendors to identify critical lines and their upset values.

Screen rooms are difficult to work with because of multiple reflections. Some customers will not "buy" radiated susceptibility testing in screen (shielded) rooms.

We have difficulties in specifying accurately what field levels are present in shielded rooms.

- The Army does not "buy" spectrum analyzers, isotropic probes, etc. for testing purposes, "nothing new since 1967."

- Specifications are so ambiguous that the government has its own interpretation while a vendor has another.

- For conducted susceptibility measurements, the Army requirement of -30 $\mathrm{dB} / \mathrm{m}$ is difficult to do because current and voltage measurements must be made at the same time. We need better current probes to do such. 
- EMI testing, antenna factors, etc. is a big con job and we don't know how to solve such with a specification.

- (We) do not advise "tailoring" of specifications, particularly for general purpose equipment.

- We have had some troubles wi th MIL STD 461B, CSO6 (Conducted Susceptibility) test requirements; the specification requirements for pulse width are too short.

- New digital systems will cause a significant impact on EMI testing. Existing specifications do not relate to digital systems.

- System measurement problems, as noted by victim-source testing:

- when the components are near their specification limit

- broad band interference to communications receivers in the $100 \mathrm{kHz}$ to UHF frequency band from own onboard generated interference occurs.

Emissions problems are, in general, where there is a clock in the component.

\section{COST OF EMI/EMC ACTIVITIES}

The survey of contractors furnishing electronic components and systems to AVRADCOM revealed the following estimated costs incurred by industry for their EMI/EMC activities. Contractor names are coded for confidentiality.

\section{Electronic Component Contractors}

Contractor A: $2 \%$ to $6 \%$ of total product development cost, $0.5 \%$ to $10 \%$ of product production cost

Contractor B: $4 \%$ of total development cost

Contractor C: $0.5 \%$ to $1.5 \%$ of total contract cost

Contractor D: $3 \%$ to $10 \%$ of product development cost

Contractor E: $3 \%$ to $7 \%$ of total development cost

Contractor F: $5 \%$ of total development cost

Contractor G: $10 \%$ of total work effort

Contractor $\mathrm{H}: \quad 10 \%$ to $20 \%$ of total environmental testing costs

Contractor I: $1 \%$ of total program development cost.

\section{Airframe Contractors}

Contractor $\mathrm{J}$ : for components, $5 \%$ to $10 \%$ of total qualification testing cost

Contractor K: $20 \%$ to $25 \%$ of total environmental testing costs. 
These costs are "ball-park" estimates; hence, their accuracy cannot be assessed. One contractor, Contractor A, performed some cost analysis work on their EMI/EMC activities. Accordingly, the estimate for Contractor A was given with no hesitation or qualification; it is probably fairly accurate.

In addition to the above costing information, the following remarks were made :

EMI testing is easily more than $\$ 100,000 /$ vehicle.

EMI testing is 3 times more costly than all other environmental (tests) together.

- Recently, $\$ 150,000$ was spent to make 3 (black) boxes EMI compatible.

- MIL STD 461 testing is too expensive for more than qualification testing--not suitable for production sampling.

- An inhouse EMI test capability is too expensive; it would cost (us) $\$ 250,000$ just to update test equipment and this does not include the cost of a screen room.

- $\quad$ EMI test costs average $\$ 15,000$ for each EMI test.

- EMI testing is done only at item qualification test level--not done with production items due to high costs.

- A screen room has been modified to have one wall covered with ferrite absorber material at a cost of $\$ 100 / \mathrm{sq} \mathrm{ft}$.

- $\quad$ EMI testing represents $1 / 3$ of total environmental testing costs.

- Outside test costs: $\$ 400 /$ day at one facility $\$ 600$ - $\$ 800 /$ day at another facility.

- (Our) typical costing is $\$ 650$ to $\$ 800 /$ day. (We) spend "a lot of time" at a test house. Outside EMI services cost $\$ 80 /$ hour.

- (We) have had a major retrofit job on an engine with EMI problems that required 2 years of engineering effort at a cost of $\$ 500,000$.

- Field levels above $60 \mathrm{~V} / \mathrm{m}$ are very costly--costing is not linearily related to field levels. High fields are very expensive.

- (Our) consultant cost is approximately $\$ 500 /$ day.

EMI testing is very expensive.

(Our) EMI testing is approximately $\$ 70 /$ hour.

Commercial and military systems require about 1000 hours of direct engineering labor for 6051 system testing. The amount of shop time for such, however, is unknown. 
- Four months of solid test time were required for 6051 system testing of a modified aircraft.

\section{ELECTROMAGRETIC HAZARDS TO PERSOMMEL AND EQUIPMENT}

The potential personnel hazards due to exposure to electromagnetic radiation are well known. So-called "safe exposure levels" have been established and the enforcement of these safeguards is handled, typically, by state and federal agencies.

Since there is a recognition of this potential hazard to personnel and equipment, several industrial contacts briefly discussed this matter during the course of the survey. Their comments follow.

- Some contractors have EM safety committees to monitor potential test hazards.

- New requirements for high field strengths, e.g., $200 \mathrm{~V} / \mathrm{m}$ and $976 \mathrm{~V} / \mathrm{m}$ pose definite safety hazards at test facilities.

- Operational EM levels appear to be, in many cases, unknown.

- (We) have a safety committee that is concerned with high level fields. Our facility only goes to $50 \mathrm{~V} / \mathrm{m}$; for higher level fields we will use outside facilities. (We are) unaware of a new $976 \mathrm{~V} / \mathrm{m}$ field requirement.

- We are concerned with the issue of EM hazards to personnel.

- We check for leakage of our screen rooms on a random basis. (We have) no formal inhouse safety program for EM hazards.

- (We) do not make leakage tests of screen rooms.

- (We are) concerned with the susceptibility of ordnance to the onboard and external EM environments. Such hazards are now receiving some emphasis.

- (We have) no special health and safety considerations for EM testing.

[NOTE: From these contacts, and to the best of our knowledge, it is not apparent where any "high fields" test facilities are or will be found for the high fields testing of future systems.]

\section{AN MBS ROLE TO IMPRONE EMI/EMC MEASUREPENTS}

Many of the contractors surveyed suggested a role for NBS so that improved EMI/EMC test methods and standards would become available. Representative contractor comments relating to this are:

- (NBS should) develop a reasonable, reliable specification with well defined testing methods. 
- A measurement tool to determine the cross coupling of cables (in the aircraft) is needed for cabling guidelines.

- (We) need more objective testing techniques.

- (There is) a need for a better multiple isotropic probe sensor system to determine (measure) the fields radiated at equipment under test--a system to cover the $14 \mathrm{kHz}$ to $18 \mathrm{GHz}$ frequency range with a $1 \mathrm{~V} / \mathrm{m}$ sensitivity.

- (NBS should) develop a reliable test method for emission and susceptibility testing using presently available shielded rooms.

- (We) need a high-field strength test method for whole system testing.

- (NBS should) develop a transportable reference antenna for checking of antenna ranges.

- NBS should come up with EMI measurement techniques, standards, etc.

- (NBS should) develop better equipment for generating known EM fields, e.g., a TEM cell.

- (NBS should) develop a replacement for the conical spiral antenna for generating EM fields.

- (NBS should) develop means to improve the repeatability of test methods.

\section{CONTRACTOR RECOMMENDATIONS FOR EMI/EMC TEST AND SPECIFICATION CHANGES AND OTHER CHANGES}

Practically all of the contractors contacted for this EMI/EMC survey had suggestions or recommendations to offer concerning the improvement of presently available specifications, standards, and test methodology. These suggestions and recommendations, in large measure, result from the current problems the contractors are experiencing in meeting contract-imposed EMI/EMC requirements. Some contractor suggestions and recommendations are as follows:

- Get rid of screen rooms.

- Tailor (EMI/EMC) requirements to the host vehicle.

- Raise EMI consciousness of all parties concerned.

- System integrators, especially, need to be EMI conscious and make sure that the final installation is the same as the test configuration.

- MIL STD 462 needs revision to better define test methods and test rel iability. 
- Definition of quantities in MIL STD 461 is inadequate and should be revised.

- Specifications should allow for use of a good spectrum analyzer.

- Remove the parallel plate test "jazz."

- Update the list of acceptable (test) equipment.

- (In the specifications) include alternative test methods such as use of a TEM cell.

- An anechoic chamber would be far better than present screen room testing.

- There is a need to standardize the parameters for test receivers: bandwidth, detector, etc.

- MIL STDS are ambiguous on defining "power line" for conducted (EMI) susceptibility and emissions testing--the physics of the item under test are (now) ignored. Accordingly, an update of the MIL STDS, e.g., units, terms, definitions, is needed.

- Criteria for susceptibility levels should be negotiated for the equipment by the user and contractor rather than using a general specification.

- Signal input and output port characteristics should be specified separately from MIL STD 461.

- A mission profile for EMI should be specified rather than using a general specification. A military expert, not a procurement specialist, should specify the EMI mission profile.

- Change the present procedure which calls for a bidder to agree to do all EMI testing to one of a "tailored" specification. Some contractors do not include total EMI test costs in their bid in the knowledge that waivers for such are available.

- Test equipment and operating equipment should also be shielded (put in a separate shielded room) during testing.

- (There is a) need for more tailoring of specifications to suit end applications, not less.

- For EMI/EMC testing (we) would like to see a large, government operated or owned EM test facility in the Southern California area to which all contractors would have access.

- The conducted emissions on signal lines is a requirement that could be tailored rather than to the present fixed level.

- There is a need for a standard format for EMI control plans. 
- Notice 4 (Army document) for MIL STD 461 is a confusing document and ought to be thrown away.

- Tailored specifications would be more reasonable for host vehicle applications.

- Clarify and quantify language, i.e., "narrowband" and "broadband."

- Update the (test) equipment list which dates back to 1964.

- MIL STDS 461 and 462:

- need better organization

- need clarification (more readable)

- the transient injection test is subject to interpretation

- there is too much testing of power lines, not enough of signal lines

- need standard signals for injection

- need tailoring

- need standard test procedure for threshold testing.

- (We) would like to see specifications written around antenna factors, using manufacturer's figures for such.

- Chattering relay test procedure would be good for inclusion in military specifications as a means to test cabling.

- Measurement needs include:

- a method of measuring fields inside a vehicle, in the cabin, in the avionics bay, etc. without disturbing the field

- detecting the effects on electroexplosive devices from all EM sources (radiated and conducted)

- since vendors sometimes take screen room liberties, there is a need to eliminate loopholes in specifications--language needs improvement to eliminate different interpretations

- a need to better define test methods and test set ups.

\section{CONCLUSIONS}

The contributions to this survey, made by many people in industry and government, were voluntary and offered in good faith. In the authors' opinion these contributions were aimed particularly at improving industrial EMI/EMC measurement assurance and at reducing the presently high costs of such assurance. The authors perceive that industry has a sincere desire to do a better job, to reduce costs and, further, is looking for help to do so. Accordingly, the following conclusions have been reached: 
A. Victim-source testing is the only current EMI test that is meaningful for whole system testing, but even it has its limits.

- Only one piece of equipment (black box) on the vehicle is tested at a time; such is not a true system test.

- Electronic system sample testing is inconsistent.

- Electronic component sample testing is almost nil.

- EMC Control Boards are not always implemented.

- There is a nonuniform configuration control between component contractors and system integrators.

- There is inadequate configuration control at Army depots.

B. There is no proof that electronic systems will perform satisfactorily in a battlefield electromagnetic environment.

- There is no evidence of a knowledge of such an electromagnetic environment.

- The electromagnetic environment in equipment bays is unknown.

- In some cases performance waivers are granted liberally.

- There are no means to create such an environment for effective whole system testing.

C. There is no correlation in test practices; thus, electronic systems overdesign, overtest, and excessive costs are possible.

- It is quite possible that component specifications are much too severe.

- Component test does not ensure system testing requirements.

- Component specifications are confusing, ambiguous, inadequate, too general, and are out of date.

- Component specifications are applied too rigorously; they could be tailored.

- Screen rooms are poor test measurement means.

- EMI consciousness and expertise declines as the product moves from the design stage to the production stage.

- There is inconsistency in permitting the use of alternate test procedures.

- There is inconsistency in the granting of specification noncompliance waivers.

[NOTE: It would appear that the "management hierarchy" of the vital electronic systems and subsystems should at least participate in the waiver granting process rather than continue with the present process. As mentioned by one contractor, "When we fully understand the system, such as a gun system, we are much more knowledgeable in deciding on or in granting waivers." This could be applied to electronic systems.] 
D. Future issues--new EMI/EMC requirements and issues.

- There will be requirements for high-level (greater than $200 \mathrm{~V} / \mathrm{m}$ testing).

- Nuclear EMP test requirements are likely to be imposed.

- There is a need for "EM effects" with composite materials test information base.

- The increased use of digital systems will impose new EMI/EMC requirements.

\section{COMPENTS}

This survey revealed a wide variety of responses from the individuals contacted. Some responses even contradict each other, e.g., "The Army's Notice 4 is a good attempt at more realistically defining EMI requirements" as opposed to "Notice 4 (the Army document) is a confusing document." The variety of comments illustrates the sometimes narrow viewpoints of certain personnel involved with EMI/EMC requirements and testing; their own interests and degree of EMI consciousness all play a significant role in establishing these particular viewpoints.

It is the authors' considered opinion that if the EMI consciousness of all parties concerned (engineering designers, managers, DOD personnel, etc.) was raised, better decisions regarding equipment design, system integration (e.g., cable control), component and system testing, performance waivers, etc. would be made; further, many of the EMI/EMC related problems would be significantly reduced. This is particularly appropriate in the light of the anticipated high fields exposure requirements for future systems.

Also, it appears that in many cases electronic warfare (EW) considerations may not be given sufficient attention. Since there is already much evidence that EW plays a significant role in weapon systems performance, and many predictions that it will play an even greater role in the future, it is our opinion that contractors (new and old alike) and users need to make a more concerted effort to properly consider EW and its relationship to electronics system performance.

The authors have also noted from this survey that aircraft for tri-service end use are often required to meet different EMI/EMC specifications and EM environments. It is not clear (to us as well as to some of the contractors) why this is the case. It would seem that a tri-service (i.e., DOD) group knowiedgeable in EMI and EMC, and representing users, could develop appropriate specifications to consolidate the different designs and test activities, thereby reducing total costs.

Another observation the authors made from this survey is that present test practices call for single-frequency testing only for EMI/EMC, i.e., one frequency at a time across a frequency band. Since systems, particularly in a battlefield environment, would be in a "swamp of frequencies," it would appear that testing should incorporate multiple frequencies in the near future. Some of these frequencies are already known or suspected to be present in an operational environment. As before, it would seem that these frequencies and their appropriate power levels, etc. could best be determined and implemented by a tri-service group. 
NBS-114A (REV, 2-8C)

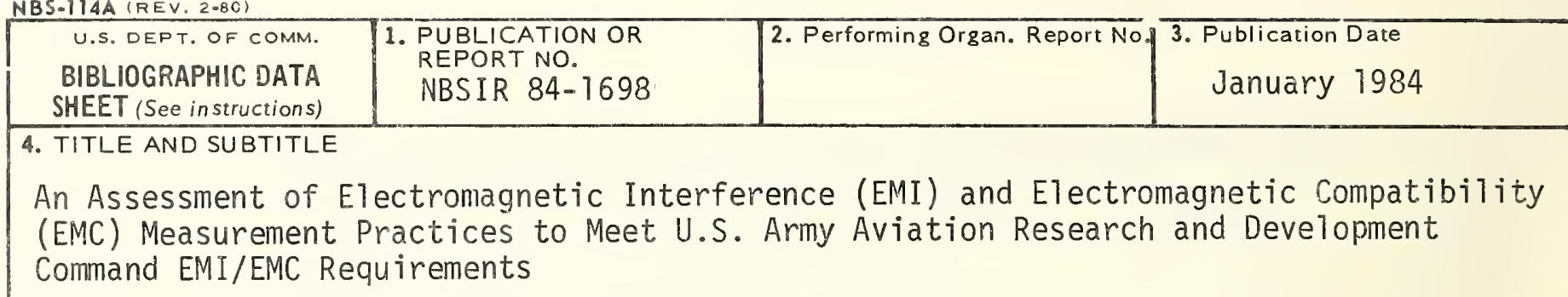

5. AUTHOR(S)

W. J. Alspach, C. K. S. Miller, G. R. Reeve

6. PERFORMING ORGANIZATION (If joint or other than NBS, see instructions)

NATIONAL BUREAU OF STANDARDS

DEPARTMEMT OF COMMERCE

WASHINGTON, D.C. 20234

9. SPONSORING ORGANIZATION NAME AND COMPLETE ADDRESS (Street, City。 State, ZIP)

7. Contract/Grant No.

U.S. Army Aviation Research and Development Command (AVRADCOM)

10. SUPPLEMENTARY NOTES

[Document describes a computer program; SF-185, FIPS Software Summary, is attached.

11. ABSTRACT (A 200-word or less factual summary of most significant information. If document includes a significant bibliography or literature survey. mention it here)

A survey of selected industrial contractors, airframe manufacturers, and electronic test and calibration firms was conducted during June - August 1982 by the Electromagnetic Fields Division, National Bureau of Standards, to assess industrial and commercial testing and measurement practices used to meet electromagnetic interference/electromagnetic compatibility (EMI/EMC) requirements of the U.S. Army Aviation Research and Development Command (AVRADCOM). This survey addressed the cost of conducting EMI/EMC tests; whether or not electronic components, subassemblies, systems, and their testing met specified AVRADCOM EMI/EMC requirements; and whether the test practices, test equipment, and EMI/EMC requirements are appropriate. The following conclusions were reached: (1) Victim-source testing, although limited, is the only current EMI test that is meaningful for whole system testing. (2) It is questionable whether electroni \& systems will perform satisfactorily in a battlefield electromagnetic environment.

(3) There is no correlation in EMI/EMC test practices; it is possible that electronic systems are overdesigned, overbuilt, and overtested. (4) Future issues such as highlevel field testing and electromagnetic pulse (EMP) need to be addressed.

12. KEY WORDS (Six to twelve entries; alphabetical order; capitalize only proper names; and separate key words by semicolons) electromagnetic compatibility (EMC); electromagnetic interference (EMI)

13. AVAILABILITY

$\square$ Unlimited

XFor Official Distribution. Do Not Release to NTIS

[ Order From Superintendent of Documents, U.S. Government Printing Office, Washington, D.C. 20402.
14. NO. OF

PRINTED PAGES

J Order From National Technical Information Service (NTIS), Springfield, VA. 22/6I

15. Price 

